\title{
The Influence of the Fourth Industrial Revolution on the Entrepreneur Leadership Attributes
}

\author{
RONNEN AVNY* \\ *Corvinus University of Budapest, Doctoral School of Business and Management; \\ ronnen.avny@stud.uni-corvinus.hu
}

DOI: $10.14267 / 978-963-503-867-1 \_01$

\begin{abstract}
Innovation, and especially innovation leadership, is a critical factor in enhancing a firm's success in today's changing markets. This research investigates changes in the entrepreneurial leadership attributes amid the fourth industrial revolution and how these changes relate to the fast pace of technology advancement. As part of the fourth industrial revolution, the barrier to introducing innovative technology has decreased due to the accessibility of high-end commercial capabilities, such as cloud computing, big-data capacities, open-source codes, and more, which reduce their need for in-house development. This research taps into the current academic knowledge gap and aims to understand how leadership traits (or attributes) may help fully exploit this significant revolution's advantages and gain a competitive advantage over rivals. This paper also contributes to the knowledge of innovation study and entrepreneur leadership study. The research utilizes automated techniques of content analysis of published interviews and entrepreneurs' biographies from recent years and the distant past. The results reveal that current entrepreneurs tend to be open-minded while avoiding rejecting innovation from other firms (avoiding "the not invented here" concept) and are willing to share the experience with the adjacent technology eco-system. The main conclusion of the research is that the entrepreneur in the current era should utilize the open innovation eco-system and gather the ingredients for innovation initiatives, and also have the ability to accurately seek the best offthe-shelf solution to use and integrate it while avoiding time- and budget-consuming development procedures.
\end{abstract}

Keywords: innovation, technology, fourth industrial revolution, entrepreneur leadership

Funding: The present publication is the outcome of the project "From Talent to Young Researcher project aimed at activities supporting the research career model in higher education," identifier EFOP-3.6.3-VEKOP-16-2017-00007 co-supported by the European Union, Hungary, and the European Social Fund. 


\section{Introduction}

When looking at the history of humankind, innovation contributes so much to achieving remarkable goals in history. It is one of the vital shaping forces of history, using human creativity to overcome any technological restrains. Innovation appears to be one of the most significant forces supporting economic development. One of the first innovation theorists was the Austrian economist Joseph Schumpeter, and he promoted the concept that innovation is the ultimate source of economic growth and hence is worthy of study (Schumpeter 1934; Fagerberg et al., 2013). Furthermore, innovation is identified as the primary driving force for companies to prosper, grow, and sustain high profitability (Drucker, 1988; Christensen, 1997).

Nowadays, in the emergence of the fourth industrial revolution, the pace of technological advancement has accelerated significantly. As stated by one of the experts in the field, Ray Kurzwell: "We will not experience 100 years of progress in the $21^{\text {st }}$ century - it will be more like 20,000 years of progress [at today's rate]" (Kurzwell, 2004 , p. 1). On the other hand, as the barrier to introducing innovative technology decreases, these phenomena are considered part of the fourth industrial revolution. The adoption rate by the public of evolving technologies has become very quick. Additionally, the ability to learn independently has increased, thanks to the extensive internet knowledgebase. This current situation enables the development of nonconventional innovations by individuals and groups that were not previously involved in innovation and means they can deploy and develop new products and new technologies much more efficiently than we used to years ago (Oxford ourworldindata.org, 2020).

This research aims to link together those three aspects: the current-time innovation paradigm; the leadership attributes of current technological firms; and the significant changes to the technological environment due to the emergence of the fourth industrial revolution. The paper's primary goal is to answer the question of how the entrepreneur adjusts their leadership attributes to cope with the current fast-changing world. Consequently, the primary question needs to be answered: what is the effect of the fourth industrial revolution on entrepreneur leadership attributes? By doing so, the research aims to understand how the changes in the current technological eco-system driven by the fourth industrial revolution impact the entrepreneur and encourage them to alter their leadership attributes to achieve their corporate objectives and succeed with innovation initiatives. This research also creates a preliminary foundation for updating the innovation paradigm related to the fourth industrial revolution, which can be appended to the existing theory of the current open, interactive innovation model. Furthermore, the research creates an opportunity for further research regarding companies' management styles related to the fourth industrial revolution. 
To lay the foundation for this research, the conventional definition of innovation should be called upon. According to Merriam-Webster, innovation is "the introduction of something new" and "a new idea, method, or device - novelty" (Miriam-Webster, 2016), even though, year after year, the definition of innovation is continuously developed (Khayyat \& Lee, 2015). A well-established definition of innovation was written by the Organization for Economic Cooperation and Development (OECD) in its Oslo Manual for Innovation: "An innovation is a new or improved product or process (or a combination thereof) that differs significantly from the unit's previous products or processes, and that has been made available to potential users (product) or brought into use by the unit (process)" (OECD, 2018, p. 20).

The remainder of the paper is organized as follows. Section 2 provides the review of the relevant literature and presents the research background, which is followed by a proposed theoretical framework. Section 3 outlines the methodology and data used to perform the analyses, while Section 4 presents the key findings and the results of each study. The paper concludes with a discussion of the theoretical and managerial implications as well as limitations and avenues for future research.

\section{Theoretical background}

Innovation is a widely spread phenomenon and not restricted only to the technology field; there are wide range of different perspectives toward innovation from different fields. The integration of those perspectives should reveal the essential characteristics of innovation. Most scholars see innovation as a process that responds to a need or opportunity, depends on creative effort, introduces novelty, and, through this, furthers the need for change, and over-all brings the invention to use (Kooij, 2018; Schon, 1967). Another point of view on innovation is by the mechanism which produced the innovation - such as the combination of old and new knowledge, the change-factor the innovation brought, or from the scholar's perspective, as depends on the source and the outcome of the innovation (Kooij, 2013, Torugsa \& Arundel, 2016; Demircioglu \& Audretsch, 2017; Brown \& Osborne, 2012; Ballot et al., 2015; Rajapathirana \& Hui, 2018).

As part of the continually changing world, innovation paradigms should be considered, and mainly their alteration throughout hundreds of years. Hence, the common segregation between the innovation paradigm-eras is to three main dominant models. The first paradigm is the linear-close model, which existed until 1970-1980, and treats innovation as a linear process starting with a scientific effort that produces the invention, then the development of the product, and finally, the marketing of the product. The second paradigm is the open interactive model (or complex system of innovation), which sees innovation as a process involving the whole system, and led to the development of broader innovation theories, such as national innovation systems 
and the Oslo manual. This dominant model existed until the beginning of the 2000s and was founded by the establishment of a dedicated university institute for the academic field of innovation, such as SPRU at the University of Sussex. The third and current leading paradigm is the open interactive model of innovation, reflecting the development of innovation theory towards a fully systemic, dynamic, non-linear process involving a range of interacting agents. This model emphasizes that knowledge flows between actors, expectations about future technology, market and policy developments, political and regulatory risks, and the institutional structures that affect incentives and barriers (Greenacre et al., 2012).

As the second focal point of the research, a distinction must be made between four industrial revolutions during modern history. Each one of them changed the economic world, and not only dramatically. The first revolution in the 18th century was driven mainly by the steam engine's invention, which led to the first large-scale manufactory of textiles, mills, steel, and more (Daemmrich, 2017; Mantoux, 1948). The second revolution occurred at the beginning of the 20th century, as the invention of the internal combustion engine led to the formation of the car industry, the system of large-scale transportation, and the emergence of mass-industry facilities. During this revolution, over 70 percent of American households had electricity, and a wave of new consumer products had entered people's lives (Daemmrich, 2017; Nye, 1992). The third revolution was the information revolution. It took place between 1960 and 1980, and the significant development was the invention of the personal computer and, with it, the ability to conduct fast and efficient data analysis. It also saw the initiation of the internet infrastructure as we know it today, giving us the ability to store and use an enormous amount of data and information and more (Daemmrich, 2017; Schwab et al., 2016).

The current revolution, the fourth industrial revolution, started at the beginning of the $21^{\text {st }}$ century and described a world where individuals move between digital domains and offline reality with the use of connected technology to enable and manage their lives. This revolution emphasizes the abilities of machines and computers to link and control the physical world (Schwab et al., 2016). However, this revolution is still in its making and represents positive and drastic changes in how we work, live, and do business. It is global and without any physical boundaries in terms of location or geographical center. This revolution is developing at a pace that is much faster and higher in intensity than the previous revolutions. This change will be historic in terms of size, speed, and scope. The drivers of this change are physical, digital, and biological. The physical change is made by autonomous vehicles, 3D printings, robots, and new materials, while the digital change is carried out by IoT and the internet of services. Digitization means automation, which in turn means that companies do not incur diminishing returns to scale, or less of them, at least. To give a sense of what this means at the aggregate level, compare Detroit in 1990 (then a major center of 
traditional industries) with Silicon Valley in 2014. In 1990, the three biggest companies in Detroit had a combined market capitalization of $\$ 36$ billion, revenues of $\$ 250$ billion, and 1.2 million employees. In 2014, the three most leading companies in Silicon Valley had a considerably higher market capital (\$1.09 trillion), generated roughly the same revenues ( $\$ 247$ billion), but with about ten times fewer employees $(137,000)$ (Schwab, 2017; Manyika \& Chui, 2014).

One of the best known and well-used definition of leadership was made by Stogdill (1950), who defined it as "the process (act) of influencing the activities of an organized group in its efforts toward goal setting and goal achievement". This definition regarding the influencing process and its outcome is also acceptable by scholars nowadays (Antonakis et al., 2003; Fiedler, 1996). The term entrepreneurship is generally associated in everyday use with an individual creating a new organization. However, in this research, the term entrepreneurship is used as the principal label to cover all research that involves "the process of uncovering and developing an opportunity to create value through innovation and seizing that opportunity without regard to either resource (human and capital) or the location of the entrepreneur - in a new or existing company" (Churchill, 1992, p. 586; Berends et al., 2016; Denton, 1999; MacVaugh \& Schiavone, 2010). There is a long term debate regarding the optimal set of leadership attributes, but there is no doubt about their importance (Goffee \& Jones, 2006). The entrepreneurial leadership attributes are considered critical factors in addressing challenging conditions and recognizing and exploiting new potential opportunities for the firm (Freeman \& Siegfried, 2015; Harrison et al., 2016).

\section{Methodology}

This research used the content analysis method to extract data about entrepreneur leadership attributes and find the variations between different eras of time and different industrial revolutions. The content analysis method is a qualitative research method that starts with actual observations and the collection of original documents and then proceeded to code layer after layer, employing analysis and comparisons to refine concepts and categories before constructing a systematic theory (Corbin \& Strauss, 1990; Fendt \& Sachs, 2008). Content analysis can analyze written, verbal, or visual communication messages (Krippendorff, 2019; Cole, 1988) and has a long history of use in different academic areas. As a research method, content analysis involves being systematic and using an objective method of describing and quantifying phenomena (Krippendorff, 1980; Sandelowski, 1995; Downe-Wamboldt, 1992).

The content analysis method is more conducive to exploring the entrepreneurs' underlying leadership attributes from documents and other written texts. This method enables us to make validated inferences from different kinds of sources and enables us to condense words into fewer content-related categories. It is assumed that when 
classified into the same groups, words, phrases, and the like share the same meaning (Krippendorff, 2019; Cavanagh 1997). An advantage of this method is that large volumes of textual data and different textual sources can be dealt with and used in collaboration (Elo \& Kyngas, 2008).

\section{Data collection and analysis}

Four firms were chosen for this research, each from a different era of time, as a suitable basis for the current preliminary research. Companies' selection is linked to the four industrial revolutions and based on an era of the innovation' paradigms and theories. Therefore, one company represents the early $20^{\text {th }}$ century; one company was chosen from the years after WW2, one from the 1980s, and finally, one from recent years, after the fourth industrial revolution. Because the industrial revolutions are linked mainly to technology advancement, the firms which included in the data recognized as the top technology leaders, which promote product type of innovation and introduce substantial novelty to the world. The researcher chose this choice of firms as they are considered good representatives of their period: Bell Labs from the first stage of the modern innovation era, Ford from the second industrial revolution, Apple from the third industrial revolution, and Zoom Video from the fourth industrial revolution. The author designed the coding process as part of the content analysis method, which is focused mainly on the leadership attributes that arise from the gathered data.

This study's data was based on digitalized documents and texts from open databases, such as the internet, newspapers, and online digital archives. Those documents include interviews with the firms' CEOs, biographies, and historical descriptions of the firms and their leaders. Therefore, due to this data's focal point, the chosen firm's leadership attributes have been extracted and analyzed. The complete dataset analysis enabled the examination of the changes in those attributes during the time.

\section{Results}

The following section introduces the results and outcome of this research, as well as the leadership attributes of the managers within the firms, while those results provide a better realization of the effect of the fourth industrial revolution on the leaders.

Bell-Labs - Bell Labs was established by AT\&T company and Western electric company in 1925 as the main R\&D unit. Its role was to support the research and development efforts of the country's then-monopolistic telephone company, American Telephone \& Telegraph (AT\&T), which was seeking to create and maintain a system that could connect any person on the globe to any other at any time.

Ford Motors - Ford Motor Company, an American automotive corporation founded in 1903 by Henry Ford and 11 associate investors. The company manufactures passenger 
cars, trucks, and tractors, as well as automotive parts and accessories. Headquarters are in Dearborn, Michigan.

Apple - an American manufacturer of personal computers, computer peripherals, and computer software. It was the first successful personal computer company and the popularizer of the graphical user interface. Headquarters are in Cupertino, California. Apple was established on April 1, 1976, by Steve Jobs and Steve Wozniak. First, the company introduces only circuit board, but after starting to sell full computer, which was much different than where familiar in the market, mainly on its design, the ability to connect it to regular screen (as TV), and ease of use.

Zoom Video - an American communications technology company headquartered in San Jose, California. It provides videotelephony and online chat services through a cloudbased peer-to-peer software platform and is used for teleconferencing, telecommuting, distance education, and social relations. At the beginning of 2020, Zoom's software usage saw a significant global increase following the introduction of quarantine measures adopted in response to the COVID-19 pandemic.

\section{Leadership attributes integration}

To link the leadership attributes to different eras of time, four technology companies were chosen, and by using a content analysis technique, the leadership attributes have been extracted from the data. As part of the data-coding process, the attributes extracted from the data were compared and linked to the acknowledged leadership attributes found in the literature. The extracted leadership attributes from all firms gathered and combined into an integrated database, which enhances the realization of the changes during the time and underscores the effects of the fourth industrial revolution on the leadership attributes.

Results showed the similarities of several leadership attributes, such as self-confidence (3 of 4), leading by example (2 of 4 ), attract excellent teams' member (3 of 4), imagination skills (2 of 4 ), view the large picture (2 of 4 ), focus and competence ( 2 of 4). On the other hand, differences can be also be discovered in several attributes, such as - empathy, choosing people who care, communicating, and endorsing the value of "not reinventing the wheel".

The dominant leadership attributes within the chosen firms were aggregated in Table 1. The dominant leadership attributes were marked with $\sqrt{ }$ sign and highlight the similarities and variations between the chosen firms' attributes. 
Table 1: Leadership attributes summary

\begin{tabular}{lllll}
\hline Leadership Attribute & $\begin{array}{c}\text { Bell- } \\
\text { Labs }\end{array}$ & Ford & $\begin{array}{c}\text { Apple } \\
\text { comp. }\end{array}$ & $\begin{array}{l}\text { Zoom } \\
\text { video }\end{array}$ \\
\hline Self Confidence & $\sqrt{ }$ & $\sqrt{ }$ & & $\sqrt{ }$ \\
Leading by examples & & & $\sqrt{ }$ & $\sqrt{ }$ \\
Attract excellent teams' member & & $\sqrt{ }$ & $\sqrt{ }$ & $\sqrt{ }$ \\
Imagination & $\sqrt{ }$ & $\sqrt{ }$ & \\
View large picture & $\sqrt{ }$ & $\sqrt{ }$ & \\
Focus and competence & & $\sqrt{ }$ & $\sqrt{ }$ \\
Empathy & & & $\sqrt{ }$ \\
Choosing people who care & & & $\sqrt{ }$ \\
Communication & & & $\sqrt{ }$ \\
Value the "not inventing the wheel" & & & $\sqrt{ }$ \\
\hline
\end{tabular}

Source: own compilation

\section{Discussion and recommendations}

The research aims to conduct a pilot survey to check the research question's validity, as the research method purposed tackling the research problem of how the entrepreneur adjusts their leadership attributes to cope with the current fast-changing world. This research answers the research question of the effect of the fourth industrial revolution on entrepreneur leadership attributes? The research results affirm several insights first - the research question can be preliminary answered so. Second, evidence was found that could affirm the tendency of avoiding the willingness to re-develop capabilities that are already existing. This evidence is linked to the preliminary assumption. Third, similarities can be observed in several leadership attributes from the leaders in a different period, which should be investigated further whether they may be adaptive to different technological periods.

\section{Theoretical contribution}

This research aims to link three domains - innovation, entrepreneurship leadership, and the fourth industrial revolution. It steps into an exciting intersection, which has hardly been explored yet, i.e., to answer the question of what changes have been brought in entrepreneur leadership attributes due to the fourth industrial revolution. To answer this question, an intensive literature review was conducted on those main topics. First, regarding innovation and the different types of innovation while concluding the innovation paradigm changes over the last two centuries. Second, regarding the past industrial revolutions and the current ones, their implications, and 
the changes have been. Third, about entrepreneurship and leadership, focusing on leadership's impact on innovation and the attributes that enhance leadership's innovation factor.

A new method to analyze and measure innovation may be introduced according to the results, thus checking the development and changing leadership attributes during the time, particularly in different industrial revolutions. Furthermore, a new perspective to look upon the firm's strategy suggested, mainly the leaders' role to adjust the firm's decision and choices at the innovation pathway. As an outcome of this research, it can be suggested that the leaders choose a collaborative mindset that shares ideas with the eco-system. This mindset may enhance the firm's ability to utilize the knowledge and the products available in the technology eco-system and focus on a more needed project while avoiding waste in unnecessary efforts.

The conclusions also influence how new start-ups can be measured and analyzed, mainly in their first stages. As demonstrated, the pace of technology nowadays, due to the fourth industrial revolution, I s much higher than it was in the past, so the firms should adjust themselves to the changing environment and gain competitive advantages. The research brings impressive leadership attributes that may be used to analyze the firm's leaders and predict its success rate with this current changing economic and technological environment.

\section{Managerial implications}

There are some valuable managerial takeaways in this research from different perspectives. The first for the firm's perspective is the need to train and improve top management and to be adapted to the present day's fast-changing environment. Second, academic institutions should enhance study programs, especially management ones, such as MBAs. Third, venture capital institutes and related funding firms should predict start-up companies' success rate in their earliest stages. This research may help guide them in this process.

The results affirm that the current era of the fourth industrial revolution forces the entrepreneur to adapt and improve their ability to use off-the-shelf technologies, accelerating his firm's innovation. The current entrepreneur must work within a close technological eco-system and share common problems and solutions to utilize the capabilities of the technology that is already available and focus only on the firm's next invention leap. Thus, today's entrepreneurs should be adept at on-the-shelf technology capabilities such as cloud computing, open-source codes, software module sharing with the public, complex algorithms for known problems, and more. A willingness to use them will enhance the firm's ability to keep up with the fast pace of the current revolution. 


\section{Limitations \& directions for future research}

This research's limitations are found in its very nature, as preliminary small-scale research consists only of several firms. The dataset should be broader, and this is the plan for the next research project. Other limitations are concerning the newness of the fourth industrial revolution as it still in progress; therefore, some of the attributes may still be developing. The proposed solution for this is to assure a similar result after the situation stabilizes. Moreover, a limitation also rests in the research method itself, as content analysis extracts the information from the written texts. Thus, this information may be biased, either from the writer's perspective, which may be the leader himself, i.e., in autobiography, or from the writer's perception of the situation, which may differ from the actual situation.

Directions for future research, other than analyzing a much broader sample, may include trying to link the leadership not only to the industrial revolution sequence but also to the industry segment and to the firm's success rate. This research may reveal a deeper layer by linking a specific set of leadership attributes to the market segment, and by combining with the firm's success rate, the outcome may be precious for future understanding of the manager's rule within the firm.

\section{References}

Antonakis, J., Avolio, B. J., \& Sivasubramaniam, N. (2003). Context and leadership: An examination of the nine-factor full-range leadership theory using the Multifactor Leadership Questionnaire. Leadership Quarterly, 14, 261-295

Ballot, G., Fakhfakh, F., Galia, F., \& Salter, A. (2015). The fateful triangle: Complementarities in performance between product, process and organizational innovation in France and the UK. Research Policy, 44(1), 217-232.

Berends, H., Smits, A., Reymen, I., \& Podoynitsyna, K. (2016). Learning while (re)configuring: Business model innovation processes in established firms. Strategic Organization, 14(3), 181-219.

Brown, K., \& Osborne, S. P. (2012). Managing change and innovation in public service organizations. Routledge.

Businessalligators.com (2017). 11 Personality Traits of Henry Ford. Business Alligators. https://www.businessalligators.com/henry-ford-personality-traits/

Cavanagh, S. (1997). Content analysis: concepts, methods and applications. Nurse researcher, $4(3), 5-16$

Churchill, N. C. (1992). Research issues in entrepreneurship. The state of the art of entrepreneurship, 579-596, Boston, MA: PWS-Kent Publishing

Chacko, E. (2020). Eric Yuan's Leadership Lessons for Building Lasting Enterprise Value. Entrepreneur $\mathscr{G}$ Innovation Exchange. https://eiexchange.com/content/eric-yuansleadership-lessons-for-building-lasting-enterprise-va

Christensen, C. (1997). Patterns in the evolution of product competition. European Management Journal, 15(2), 117-127. 
Cole, F. L. (1988). Content analysis: process and application. Clinical nurse specialist, 2(1), 53-57

Corbin, J. M., \& Strauss, A. (1990). Grounded theory research: Procedures, canons, and evaluative criteria. Qualitative sociology, 13(1), 3-21.

Downe-Wamboldt, B. (1992). Content analysis: method, applications, and issues. Health care for women international, 13(3), 313-321

Denton, D.W. (1999). The attraction-selection-attrition model of organizational behavior and the homogeneity of managerial personality. Current Research in Social Psychology, Vol. 4 No. 8, pp. 146-59.

Daemmrich, A. (2017). Invention, innovation systems, and the Fourth Industrial Revolution. Technology $\&$ Innovation, 18(4), 257-265.

Demircioglu, M. A., \& Audretsch, D. B. (2017). Conditions for innovation in public sector organizations. Research policy, 46(9), 1681-1691.

Dosi, G. (2012). Economic coordination and dynamics: Some elements of an alternative evolutionary paradigm (No. 2012/08). LEM Working Paper Series.

Drake, A. (n.d.). 5 Ways to Use Empathy in Leadership From Zoom CEO, Eric Yuan. G2.Com. https://learn.g2.com/hub/reach-2019/eric-yuan

Drucker, P. F. (1988). The coming of the new organization.

Editor. (n.d.). Steve Jobs and the Early Apple Years. Https://Www.iProgrammer.Info/History/People/104-Steve-Jobs-Apple.Html. Retrieved January 17, 2021, from https://www.i-programmer.info/history/people/104-steve-jobs-apple.html

Elo, S., \& Kyngäs, H. (2008). The qualitative content analysis process. Journal of advanced nursing, 62(1), 107-115

Fagerberg, J., Martin, B., \& Andersen, E. S. (2013). Innovation Studies: Evolution \& Future Challenges, $1-230$.

Fendt, J., \& Sachs, W. (2008). Grounded theory method in management research: Users' perspectives. Organizational Research Methods, 11(3), 430-455.

Fiedler, F. E. (1996). Research on leadership selection and training: One view of the future. Administrative science quarterly, 241-250.

Freeman, D., \& Siegfried Jr, R. L. (2015). Entrepreneurial leadership in the context of company start-up and growth. Journal of Leadership Studies, 8(4), 35-39.

Ford inc. (n.d.). Henry Ford Biography. Retrieved from https://corporate.ford.com/articles/history/henry-ford-biography.html

Goffee, R., \& Jones, G. (2006). Getting personal on the topic of leadership: Authentic selfexpression works for those at the top. Human Resource Management International Digest, 14(4), 32-34. https://doi.org/10.1108/09670730610666382

Greenacre, P., Gross, R., \& Speirs, J. (2012). Innovation Theory: A review of the literature. Imperial College Centre for Energy Policy and Technology (ICEPT), (May), 1-49. https://doi.org/10.1016/j.surfcoat.2008.04.067

Harrison, C., Paul, S., \& Burnard, K. (2016). Entrepreneurial Leadership: A Systematic Literature Review. International Review of Entrepreneurship, 14(2), 14(2), 235-264. Retrieved from https://www.researchgate.net/publication/331589807

Henry Ford - Visionaries on Innovation - The Henry Ford. (n.d.), Thehenryford.Org. Retrieved January 17, 2021, from https://www.thehenryford.org/explore/stories-ofinnovation/visionaries/henry-ford/ 
Himmel, R. (2013, April 18). What Personality Traits Made Steve Jobs

Successful? Entrepreneur. https://www.entrepreneur.com/answer/226410

Huddleston, T. (2020, March 30). Zoom's founder left a 6-figure job because he wasn't happy - and following his heart made him a billionaire. CNBC.

https://www.cnbc.com/2019/08/21/zoom-founder-left-job-because-he-wasnt-happybecame-billionaire.html

Khayyat, N. T., \& Lee, J. D. (2015). A measure of technological capabilities for developing countries. Technological Forecasting and Social Change, 92, 210-223.

Krippendorff, K. (1980). Validity in content analysis.

Krippendorff, K. (2019). The changing landscape of content analysis: Reflections on social construction of reality and beyond. Communication 85 Society, 47, 1-27.

Kurzweil, R. (2004). The law of accelerating returns. In Alan Turing: Life and legacy of a great thinker (pp. 381-416). Springer, Berlin, Heidelberg.

Levy, S. (n.d.). Apple Inc. / History, Products, Headquarters, \& Facts. Encyclopedia Britannica. Retrieved from https://www.britannica.com/topic/Apple-Inc

MacVaugh, J., \& Schiavone, F. (2010). Limits to the diffusion of innovation. European journal of innovation management, 13(2), 197-221.

Mantoux, P. (1947). The Industrial Revolution in the Eighteenth Century. The Macmillan Company

Manyika, J., \& Chui, M. (2014). Digital era brings hyperscale challenges. Ft.com. Retrieved 25 March 2021, from https://www.ft.com/content/f30051b2-1e36-11e4-bb6800144 feabdc0.

Merriam-Webster Eds. (Ed.). (2016). The Merriam-Webster Dictionary (Vol. 1st edition). Turtleback.

Noel, V. (2020). Leadership skills and qualities of Steve Jobs, which everyone should learn from. Medium. https://medium.com/@vishalnoel7/top-6-attributes-of-steve-jobs-thatmake-him-a-great-leader-1175eba08e0c

Nye, D. E. (1990). Electrifying America: Social Meaning of a New Technology.

OECD/Eurostat. (2018). Oslo Manual 2018: Guidelines for Collecting, Reporting and Using Data on Innovation, 4th Edition, The Measurement of Scientific, Technological and Innovation Activities. Handbook of Innovation Indicators and Measurement. https://doi.org/10.1787/9789264304604-en

Patel, B. (2018, September 6). "5 CEO Tips On Leading Large Teams" with Zoom's CEO Eric Yuan. Medium. https://medium.com/authority-magazine/5-ceo-tips-on-leadinglarge-teams-with-zooms-ceo-eric-yuan-28d505d045f9

Rajapathirana, R. J., \& Hui, Y. (2018). Relationship between innovation capability, innovation type, and firm performance. Journal of Innovation $\&$ Knowledge, 3(1), 4455 .

Ritchie, H., \& Roser, M. (2017). Technology Adoption. Retrieved from https://ourworldindata.org/technology-adoption

Sandelowski, M. (1995). Qualitative analysis: What it is and how to begin. Research in nursing 83 health, 18(4), 371-375

Schön, D. A. (1967). Technology and change: The new Heraclitus, Oxford: Pergamon Press. 
Schumpeter, J. A. (1934). The Theory Of Economic Development: An Inquiry Into Profits, Capital, Credit, Interest, And The Business Cycle (Harvard Economic Studies).

Harvard University Press.

Schwab, K. (2017). The fourth industrial revolution. Crown Publishing.

Schwab, K. \& World Economic Forum. (2016, January 14). The Fourth Industrial

Revolution: what it means and how to respond. World Economic Forum.

https://www.weforum.org/agenda/2016/01/the-fourth-industrial-revolution-what-itmeans-and-how-to-respond/

The Editors of Encyclopaedia Britannica. (n.d.). Ford Motor Company / History \& Facts. Encyclopedia Britannica. Retrieved from https://www.britannica.com/topic/FordMotor-Company

The Real Leadership Lessons of Steve Jobs. (2014). Harvard Business Review. https://hbr.org/2012/04/the-real-leadership-lessons-of-steve-jobs

Torugsa, N., \& Arundel, A. (2016). Complexity of innovation in the public sector: A workgroup-level analysis of related factors and outcomes. Public Management Review, 18(3), 392-416.

UK Essays. (n.d.). Leadership Traits Of Steve Jobs. UKEssays.Com. Retrieved from https://www.ukessays.com/essays/media/outstanding-leadership-traits-of-steve-jobsmedia-essay.php?vref $=1$

van der Kooij, B. J. J. G. (2013). Innovation Defined: A Survey. SSRN Electronic Journal, (April 2013), 1-48. https://doi.org/10.2139/ssrn.2265782

van der Kooij, B. J. G. (2018). Search for a Common Ground in the Fogs of Innovation Definitions. SSRN Electronic Journal, 1-33. https://doi.org/10.2139/ssrn.3139486

Wikipedia (2021). Zoom Video Communications. Wikipedia. https://en.wikipedia.org/wiki/Zoom_Video_Communications

Wingard, J. (2019, May 16). The Ascent Of Zoom CEO Eric Yuan: Leadership Lessons In Execution \& Authenticity. Forbes.

https://www.forbes.com/sites/jasonwingard/2019/05/15/the-ascent-of-zoom-ceo-ericyuan-holds-leadership-lessons-for-all/?sh $=62686 \mathrm{~d} 2 \mathrm{f} 7393$

Writer, S. (2020, May 22). Bold Leader Spotlight: Henry Ford, Captain of Industry. Bold Business. https://www.boldbusiness.com/human-achievement/bold-leader-spotlighthenry-ford-captain-of-industry/ 